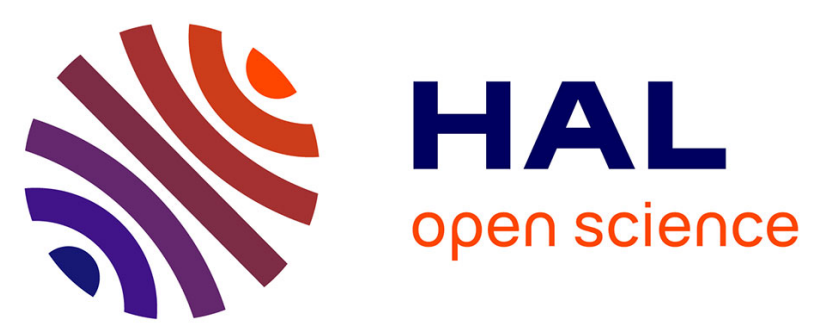

\title{
An educational intervention about the classification of penicillin allergies: effect on the appropriate choice of antibiotic therapy in pregnant women
}

C. Thellier, Damien Subtil, D. Pelletier de Chambure, Bruno Grandbastien, C. Catteau, A. Beaugendre, D. Poitrenaud, Anne Prevotat, Pierre Richart, Karine Faure, et al.

\section{To cite this version:}

C. Thellier, Damien Subtil, D. Pelletier de Chambure, Bruno Grandbastien, C. Catteau, et al.. An educational intervention about the classification of penicillin allergies: effect on the appropriate choice of antibiotic therapy in pregnant women. International Journal of Obstetric Anesthesia, 2020, International journal of obstetric anesthesia, 41, pp.22-28. 10.1016/j.ijoa.2019.07.005 * hal-02566589

\section{HAL Id: hal-02566589 \\ https://hal.univ-lille.fr/hal-02566589}

Submitted on 7 May 2020

HAL is a multi-disciplinary open access archive for the deposit and dissemination of scientific research documents, whether they are published or not. The documents may come from teaching and research institutions in France or abroad, or from public or private research centers.
L'archive ouverte pluridisciplinaire HAL, est destinée au dépôt et à la diffusion de documents scientifiques de niveau recherche, publiés ou non, émanant des établissements d'enseignement et de recherche français ou étrangers, des laboratoires publics ou privés. 
An educational intervention about classification of penicillin allergies: effect on the appropriate choice of antibiotic therapy in pregnant women

C. Thellier ${ }^{a}$, D. Subtil ${ }^{a, b}$, D. Pelletier de Chambure, B. Grandbastien ${ }^{b, d}$ C. Catteau ${ }^{a}, A$. Beaugendre $^{a}$, D. Poitrenaud ${ }^{e}$, A. Prevotat ${ }^{c}$, P. Richart, K. Faure ${ }^{e, g}$, R. Le Guern $^{g, h}$

${ }^{a}$ Univ. Lille, CHU Lille, Hôpital Jeanne de Flandre, Pôle Femme Mère Nouveau-né, F-59000 Lille, France

${ }^{b}$ Univ. Lille, EA 2694 Santé Publique, Epidémiologie et Qualité des Soins, F-59000 Lille France

${ }^{c}$ Univ. Lille, CHU Lille, Pneumo-allergologie Hôpital Calmette, F-59000 Lille, France

${ }^{d}$ Univ. Lille, CHU Lille, Service de Gestion du Risque Infectieux et des Vigilances, F-59000 Lille, France

${ }^{e}$ Univ. Lille, CHU de Lille, Service de Maladies Infectieuses, F-59000 Lille France

${ }^{f}$ Univ. Lille, CHU Lille, Pôle d'Anesthésie-Réanimation, F-59000 Lille, France

${ }^{g}$ Univ. Lille, EA 7366, Recherche translationnelle, relations hôte-pathogènes, F-59000 Lille, France

${ }^{h}$ Univ. Lille, CHU Lille, Laboratoire de Bactériologie-Hygiène, Institut de Microbiologie, F59000 Lille, France

\section{Corresponding author:}

Rémi Le Guern

Univ. Lille, CHU Lille, Laboratoire de Bactériologie-Hygiène, Institut de Microbiologie, F-59000

Lille, France

Tel: 33 +320445480 - Fax: 33 +32044 4895

e-mail: remi.leguern@chru-lille.fr

Short title: Classification of penicillin allergies in pregnant women (56 characters)

Funding: This research did not receive any specific grant from funding agencies in the public, commercial, or not-for-profit sectors.

Keywords: educational intervention; penicillin allergy; clindamycin; cefazolin

Word count $=2280$ words

Word count $=233$ words 


\begin{abstract}
Background: Most pregnant women self-reporting penicillin allergy are not truly penicillinallergic, and this misunderstanding often leads to administration of inappropriate antibiotic therapy. Decision algorithms have been developed to guide antibiotic selection, but major discrepancies have been reported between guidelines and clinical practice. We aimed to optimize the prescription of antibiotics for pregnant women who self-reported penicillin allergy, using an educational intervention about classification of penicillin allergies that targeting gynecologists, anesthesiologists and midwives.

Methods: This quasi-experimental study intended to assess the effect of an educational intervention about penicillin allergy classification. For 6 months, a combination of two strategies were used: dissemination of printed educational materials and group education. The principal endpoint was the appropriateness of the antibiotic therapy, defined in advance for each level of allergic risk.

Results: The preintervention portion of the study included 903 women; one year after its conclusion, the postintervention portion began and included 892 women. The prevalence of selfreported penicillin allergies was stable over the two periods (6.8\% before vs. $5.4 \%$ after, $P=0.24)$. The clinical classification of penicillin allergies was more often used after the educational intervention ( 68.0 vs. $100.0 \%, P<0.001)$. The appropriateness of the antibiotic therapy prescribed for self-reported penicillin allergic-women increased significantly between the two periods $(5 / 29$ $(17.2 \%)$ vs. $18 / 27(66.7 \%), P<0.001)$.

Conclusion: An educational intervention about penicillin allergy classification was associated with an improvement in choice of appropriate antibiotic therapy in women who reported penicillin allergy.
\end{abstract}




\section{INTRODUCTION}

Worldwide, infection is one of the leading causes of both maternal and neonatal mortality ${ }^{1}$. Antibiotics have made maternal sepsis related mortality a rare event, and the frequency of maternal-fetal infections has fallen substantially ${ }^{2}$. Overall, $15 \%$ of pregnant women receive antibiotics during pregnancy ${ }^{3}$ and $55 \%$ at delivery ${ }^{4}$. $\beta$-lactams are among the most useful antibiotics, because of their efficacy, tolerability, and safety for use during pregnancy. Streptococcus agalactiae is responsible for more than half of maternal-fetal infections, and almost all isolates are highly susceptible to penicillins ${ }^{6}$.

Around 5 to $10 \%$ of adults report a history of penicillin allergy ${ }^{7}$; the frequency among pregnant women is similar ${ }^{8,9}$. Penicillin-allergic patients often receive macrolides, which can result in lower efficacy, especially as resistance is present in 20 to $30 \%$ of cases for S. agalactiae $^{10}$. However, between 80 and $90 \%$ of women who self-report a history of penicillin allergy able are actually able to tolerate penicillin and could be treated with a $\beta$-lactam ${ }^{11}$. Decision algorithms have been developed to guide selection of appropriate antibiotic in patients with suspected penicillin allergy ${ }^{12,13}$.

In pregnant women, specific guidelines were issued for the prevention of S. agalactiae perinatal infection ${ }^{14}$. According to these guidelines, women are at high risk of anaphylaxis if they report at least one of the following four clinical responses following administration of a penicillin or a cephalosporin: anaphylaxis, angioedema, respiratory distress, or urticaria. Among those who selfreported penicillin allergy but did not present these symptoms, treatment by cefazolin (a firstgeneration cephalosporin) is recommended. However, in clinical practice, only $14 \%$ to $44 \%$ of the women at low risk for anaphylaxis received cefazolin for the prevention of S. agalactiae perinatal infection $^{8,15}$.

Another frequent cause of antibiotic prescription during pregnancy is prophylaxis for cesarean delivery. First-line treatment is cefazolin, except for women at high risk of anaphylaxis following administration of penicillins or cephalosporins ${ }^{16}$. However, in a recent study more than $50 \%$ of the women that received alternative antibiotics were not at high risk of anaphylaxis and should have received cefazoline ${ }^{17}$. Thus, there can be major discrepancies between guidelines and clinical practice in pregnant women.

The objective of our study was to optimize the prescription of antibiotics for pregnant women self-reporting penicillin allergy, through an educational intervention about classification of penicillin allergies targeting gynecologists, anesthesiologists and midwives. 


\section{METHODS}

This quasi-experimental study intended to assess the effect of an educational intervention about penicillin allergy classification. The target population of the intervention was the hospital staff potentially prescribing antibiotics for pregnant women (gynecologists, anesthesiologists, midwives). It took place in a single university hospital. Approval of the study was obtained from the French Data Protection Authority (CNIL) under number DEC2015-86.

One year before the beginning of the study, we proposed a standardized protocol of penicillin allergy classification based on allergy history. This classification was validated by interdisciplinary consensus between the allergy, anesthesiology, bacteriology, infectious diseases, gynecology and obstetrics teams of our hospital. Three levels of risk were defined, associated with recommendations of antibiotic therapy (Table 1). Level 0 is defined by symptoms not usually associated with penicillin allergies. In this situation, treatment by penicillin is recommended if indicated. At level 1, the existence of a severe allergic reaction is considered improbable; penicillins are contraindicated but cefazolin is recommended. At level 2, the probability of a severe allergic reaction is judged high and all $\beta$-lactams are contraindicated. The penicillin allergy classification was available in local prescribing resources from June 2014.

We conducted an educational intervention to bring this classification to the staff's attention. For 6 months (from July 2015 to December 2015), a combination of two strategies were used: dissemination of printed educational materials and group education. Posters of the classification were displayed in the prenatal and anesthesia examining rooms as well as in the delivery rooms. It was included in the pocketbook given to medical residents on their first day of arrival. The classification was formally presented to all the hospital staff potentially prescribing antibiotics for pregnant women. During weekdays morning reports, on which complicated deliveries from the last 24 hours are discussed, each time penicillin allergy was reported the penicillin allergy classification was reminded and feedback was provided. After the intervention period, the penicillin allergy classification continued to be presented to the new staff joining (mainly medical residents), but there was no specific focus during weekday morning reports.

To measure the effect of the educational intervention, two periods were studied. The preintervention period took place from March 1 to May 29, 2015. The postintervention period began from August 1 to October 26, 2016. Consecutive women having given birth during these periods were eligible to inclusion, even if the pregnancy had resulted in termination or an in-utero death. Only women with multiple pregnancies were excluded. Maternal and neonatal data were collected from the medical files: social and demographic characteristics, obstetric history, data related to pregnancy, delivery, and the newborn. All the antibiotic prescriptions during pregnancy or delivery were also collected for all women who reported penicillin allergy.

The antibiotic therapy was considered appropriate when the allergy was classified according to the three predefined levels of risk, and the recommended antibiotic therapy was prescribed; it was considered incorrect in all other cases, including when the allergic risk level was not reported in the medical file. When penicillin was indicated as a first-line treatment (e.g. prevention of $S$. agalactiae neonatal disease), the recommended antibiotic therapy was penicillin for risk level 0 , cefazolin for risk level 1 , non- $\beta$-lactams for risk level 2 . When cefazolin was indicated as a first-line treatment (e.g. antibiotic prophylaxis for cesarean section), the recommended antibiotic therapy was cefazolin for risk level 0 and 1 , non- $\beta$-lactams for risk level 2 .

The statistical analysis was performed with $\mathrm{R}$ Software ${ }^{18}$. Qualitative variables were compared with Fisher's exact test or the Chi-2 test, and continuous variables with Student's t-test. Percentages are reported in parentheses, and means are reported with the standard deviation of the distribution. The principal endpoint was the appropriateness of the antibiotic therapy prescribed to women having given birth, defined in advance for each level of allergic risk. Secondary study outcome was the percentage of self-reported penicillin allergies correctly classified in the medical records. A $P$-value less than 0.05 was considered statistically significant. 


\section{RESULTS}

There were 998 deliveries during the preintervention period and 971 deliveries in the postintervention period (Figure 1). After exclusion of multiple pregnancies and of records that could not be located, 903 and 893 women, respectively, were included.

The women in both study periods were representative of the hospital's patient population. The two groups were comparable for almost all their general and obstetric characteristics (Table 2 ), except for a slight increase in body mass index (BMI) and a reduction in the preterm delivery rate. Reported allergies to penicillin were stable (6.8 vs. $5.4 \%, P=0.24)$.

Among the women who reported penicillin allergy, the penicillin allergy classification was more frequently used in the postintervention period (68.9 vs. $100 \%, P<0.001)$ (Table 3 ). Around half the women who reported penicillin allergy received at least one antibiotic during pregnancy or delivery, this percentage did not vary significantly between the study periods (47.5 vs. $56.3 \%, P=0.44)$.

Following the educational intervention, the rate of appropriate antibiotic treatment increased from 17.2 to $66.7 \%(P<0.001)$ (Table 4$)$. In particular, the rate of cefazolin prescription increased from 7.1 to $38.5 \%$ for the women at a low-risk level, though it was not statistically significant $(P=0.07)$. Antibiotics were prescribed principally at delivery. No anaphylactic reactions were reported.

Table 5 presents the classes of antibiotics administered during each period, according to the women's allergy risk level. In women for whom a serious allergy was considered improbable (risk level 1), cefazolin use increased between the two periods but this was not significant ( $7.1 \%$ before vs. $38.5 \%$ after, $P=0.07)$. 


\section{DISCUSSION}

We investigated the impact of an educational intervention on selection of appropriate antibiotic therapy among women who reported penicillin allergy. Selection of appropriate of antibiotic therapy increased significantly between the two periods (from $17.2 \%$ to $66.7 \%$ ). Our study suggests that an educational intervention could increase the use of a penicillin allergy classification among gynecologists, anesthesiologists, and midwives.

Educational interventions about penicillin allergy have been previously described in the literature $^{19,20}$. An electronic survey of 323 inpatient providers showed baseline knowledge deficiencies, as $42 \%$ reported no prior education in penicillin allergy ${ }^{20}$. After a 10 -min educational presentation introducing a penicillin allergy clinical guideline, preparedness to determine if an allergy was severe improved from $77 \%$ to $92 \%(P=0.03)$. Preparedness to prescribe antibiotics to patients with penicillin allergy slightly improved from $66 \%$ to $76 \%$, but this was not statistically significant $(P=0.13)^{20}$. Another study proposed the use of a computerized algorithm to help healthcare professionals to identify low-risk patients with an inaccurate label of penicillin allergy $^{19}$. However, as this study only demonstrated the feasibility of implementing a computerized algorithm, its effect in clinical practice remains unknown.

The proportion of pregnant women in our study who reported penicillin allergy was around $6 \%$ during both periods. This proportion is similar to the general adult population, ranging from 5 to $10 \%^{21-23}$. The prevalence of penicillin allergies reported among pregnant women was recently assessed at $8.4 \%$ among 170,000 women in California ${ }^{4}$. The prevalence of anaphylaxis during pregnancy is much lower, estimated at 1.6 per 100000 maternities, and is caused by antibiotics in $49 \%$ of cases $^{24}$. In the UK, the primary antibiotics associated with perioperative anaphylaxis were co-amoxiclav (a $\beta$-lactam) and teicoplanin ${ }^{25}$. In particular, teicoplanin was 17fold more likely to cause anaphylaxis than other antibiotics. Therefore, avoiding penicillin in patients who are not truly penicillin-allergic can paradoxically cause more anaphylactic reactions if teicoplanin is used as an alternative.

Among pregnant women, antibiotics are often prescribed during delivery, especially to prevent perinatal S. agalactiae ${ }^{4}$. The Centers for Disease Control (CDC) issued specific guidelines in 1996, and updated them in 2002 and $2010^{14}$. The current guidelines call for pregnant women who are colonized by $S$. agalactiae at the end of the third trimester to be questioned about the specific types of allergic reaction. The use of penicillin or cephalosporins is contraindicated among women who reported severe reactions such as anaphylaxis, angioedema, respiratory distress, or urticaria following administration of penicillins or cephalosporins. These women should receive clindamycin or vancomycin during labor, depending on the antimicrobial susceptibility of the S. agalactiae strain. Among pregnant women self-reporting penicillin allergy but without these severe symptoms, treatment by cefazolin (a first-generation cephalosporin) is recommended.

Compared with the CDC classification, our local policy classification was used for this study and covers a broader range of indications for antibiotic therapy during pregnancy and delivery. It also introduces a level 0 of risk for women with symptoms not associated with penicillin allergy (mycosis, fever, vertigo, diarrhea). Isolated diarrhea following $\beta$-lactams administration was not considered to be associated with allergy in our classification. Diarrhea might be observed in allergies, but is rarely the only presenting sign ${ }^{26}$. Moreover, diarrhea occurs in $10 \%$ of patients treated by amoxicillin-clavulanic $\operatorname{acid}^{27}$, leading us to include it in risk level 0 (probably not an allergy) ${ }^{13}$. Risk level 0 covered $12.5 \%$ of the women during our postintervention period. Such women should be able to receive penicillin, as recommended during labor for colonization by $S$. agalactiae.

We selected cefazolin for women who presented with delayed urticaria after penicillin administration, although the CDC guidelines from 2010 recommend not using $\beta$-lactams in this situation. A recent decision algorithm for presumed $\beta$-lactam allergy recommended cefazolin for mild symptoms after exposure to penicillin, that included: delayed urticaria and any skin rash occurring $>2 \mathrm{~h}$ after exposure ${ }^{13}$. Indeed, the most common reaction is the type IV allergic reaction, which is T-cell-mediated and occurs from $2 \mathrm{~h}$ to several days after the last drug administration. 
These nonimmediate reactions usually include skin reactions like delayed urticaria or maculopapular exanthema ${ }^{28}$ and pose no risk of anaphylaxis ${ }^{13}$.

Cross-reactions between penicillins and cephalosporins are rare $^{29}$, and $90 \%$ of them are due to a similarity in the R1 side chain, target of an IgE-mediated immune-allergic reaction ${ }^{30}$. Cefazolin does not share this side chain with the penicillins, nor do the third and fourth generation cephalosporins $^{31}$. In two retrospective studies of penicillin-allergic patients treated by cefazolin $(n=128$ and $n=413)$, only one patient presented an anaphylactic reaction ${ }^{32,33}$. In another study based on electronic health records, out of 65,915 patients with a history of penicillin allergy, only 3 cases of cephalosporin-associated anaphylaxis $(0.004 \%)$ were documented ${ }^{34}$. Therefore, cefazolin can be safely administered to most of the patients with a history of penicillin allergy, in case of mild symptoms occurring $>2 \mathrm{~h}$ after exposure to penicillin.

The quasi-experimental design of our study is one of its limitations. Indeed, the improved appropriateness of antibiotic therapy observed over the two periods might be associated with other factors than the educational intervention. This hypothesis nonetheless appears improbable given the short interval between the two periods and the extent of the difference observed (a year apart and an increase in the appropriateness of antibiotic therapy from 17.2 to $66.7 \%$ ). Moreover, no major modification of our management protocols took place between the two periods. Patients characteristics were similar, except for a moderate rise in BMI and a reduction in the preterm delivery rate. An increase in BMI was observed among pregnant women throughout France during the same period ${ }^{35}$. However, the pre-term birth rate slightly increased in France between $2010(6.5 \%)$ and $2016(7.5 \%)^{35}$. Another limitation of this study is its monocentric design. This may limit the generalization of our findings.

In conclusion, this study showed that an educational intervention about penicillin allergy classification was associated with an improvement in the selection of appropriate antibiotic therapy in women who reported penicillin allergy. Further studies are warranted to identify the most effective educational strategies to improve the management of patients with suspected penicillin-allergy.

Figure Legend:

Figure 1: Flow chart of the study. 


\section{REFERENCES}

1. Sachs BP, Brown DA, Driscoll SG, et al. Hemorrhage, infection, toxemia, and cardiac disease, 1954-85: causes for their declining role in maternal mortality. American journal of public health 1988; 78: 671-675.

2. WHO Recommendations for Prevention and Treatment of Maternal Peripartum Infections. Geneva, 2015.

3. Jacob L, Kalder M, Kostev K. Prevalence and predictors of prescription of antibiotics in pregnant women treated by gynecologists in Germany. Int $\mathrm{J}$ Clin Pharmacol Ther 2017; 55: 643-649.

4. Desai SH, Kaplan MS, Chen Q, Macy EM. Morbidity in Pregnant Women Associated with Unverified Penicillin Allergies, Antibiotic Use, and Group B Streptococcus Infections. Perm J 2017; 21.

5. Thibaudon Baveux C, Stroebel Noguer A, Boulard Mallet I, et al. [Prevention of early-onset group B streptococcus neonatal diseases. The 2005 experience of the Lille University Health Center]. J Gynecol Obstet Biol Reprod (Paris) 2008; 37: 392399.

6. Hays C, Louis M, Plainvert C, et al. Changing Epidemiology of Group B Streptococcus Susceptibility to Fluoroquinolones and Aminoglycosides in France. Antimicrob Agents Chemother 2016; 60: 7424-7430.

7. Joint Task Force on Practice P, American Academy of Allergy A, Immunology, et al. Drug allergy: an updated practice parameter. Ann Allergy Asthma Immunol 2010; 105: 259-273.

8. Van Dyke MK, Phares CR, Lynfield R, et al. Evaluation of universal antenatal screening for group B streptococcus. N Engl J Med 2009; 360: 2626-2636.

9. Wendel GD, Jr., Stark BJ, Jamison RB, Molina RD, Sullivan TJ. Penicillin allergy and desensitization in serious infections during pregnancy. $\mathrm{N}$ Engl $\mathrm{J}$ Med 1985; 312: 1229-1232.

10. Six A, Firon A, Plainvert C, et al. Molecular Characterization of Nonhemolytic and Nonpigmented Group B Streptococci Responsible for Human Invasive Infections. $\mathrm{J}$ Clin Microbiol 2016; 54: 75-82.

11. Blumenthal KG, Shenoy ES, Varughese CA, Hurwitz S, Hooper DC, Banerji A. Impact of a clinical guideline for prescribing antibiotics to inpatients reporting penicillin or cephalosporin allergy. Ann Allergy Asthma Immunol 2015; 115: 294-300 e292.

12. Vorobeichik L, Weber EA, Tarshis J. Misconceptions Surrounding Penicillin Allergy: Implications for Anesthesiologists. Anesth Analg 2018; 127: 642-649.

13. Hermanides J, Lemkes BA, Prins JM, Hollmann MW, Terreehorst I. Presumed beta-Lactam Allergy and Cross-reactivity in the Operating Theater: A Practical Approach. Anesthesiology 2018; 129: 335-342.

14. Verani JR, McGee L, Schrag SJ, Division of Bacterial Diseases NCfl, Respiratory Diseases CfDC, Prevention. Prevention of perinatal group B streptococcal disease--revised guidelines from CDC, 2010. MMWR Recommendations and reports : Morbidity and mortality weekly report Recommendations and reports / Centers for Disease Control 2010; 59: 1-36.

15. Briody VA, Albright CM, Has P, Hughes BL. Use of Cefazolin for Group B Streptococci Prophylaxis in Women Reporting a Penicillin Allergy Without Anaphylaxis. Obstet Gynecol 2016; 127: 577-583. 
16. American College of O, Gynecologists. ACOG Practice Bulletin No. 120: Use of prophylactic antibiotics in labor and delivery. Obstet Gynecol 2011; 117: 14721483.

17. Kawakita T, Huang CC, Landy HJ. Choice of Prophylactic Antibiotics and Surgical Site Infections After Cesarean Delivery. Obstet Gynecol 2018; 132: 948-955. 18. R Core Team. R: A language and environment for statistical computing. 2013.

19. Krishna MT, Huissoon AP, Li M, et al. Enhancing antibiotic stewardship by tackling "spurious" penicillin allergy. Clin Exp Allergy 2017; 47: 1362-1373.

20. Blumenthal KG, Shenoy ES, Hurwitz S, Varughese CA, Hooper DC, Banerji A. Effect of a drug allergy educational program and antibiotic prescribing guideline on inpatient clinical providers' antibiotic prescribing knowledge. J Allergy Clin Immunol Pract 2014; 2: 407-413.

21. Borch JE, Andersen KE, Bindslev-Jensen C. The prevalence of suspected and challenge-verified penicillin allergy in a university hospital population. Basic Clin Pharmacol Toxicol 2006; 98: 357-362.

22. Macy E. Elective penicillin skin testing and amoxicillin challenge: effect on outpatient antibiotic use, cost, and clinical outcomes. J Allergy Clin Immunol 1998; 102: $281-285$.

23. Solensky R, Earl HS, Gruchalla RS. Clinical approach to penicillin-allergic patients: a survey. Ann Allergy Asthma Immunol 2000; 84: 329-333.

24. McCall SJ, Bunch KJ, Brocklehurst $P$, et al. The incidence, characteristics, management and outcomes of anaphylaxis in pregnancy: a population-based descriptive study. BJOG : an international journal of obstetrics and gynaecology 2018; 125: 965-971.

25. Harper NJN, Cook TM, Garcez T, et al. Anaesthesia, surgery, and lifethreatening allergic reactions: epidemiology and clinical features of perioperative anaphylaxis in the 6th National Audit Project (NAP6). Br J Anaesth 2018; 121: 159171.

26. Ellis AK, Day JH. Diagnosis and management of anaphylaxis. CMAJ 2003; 169: 307-311.

27. Bush LM, Johnson CC. Ureidopenicillins and beta-lactam/beta-lactamase inhibitor combinations. Infectious disease clinics of North America 2000; 14: 409-433, ix.

28. Cernadas JR, Brockow K, Romano A, et al. General considerations on rapid desensitization for drug hypersensitivity - a consensus statement. Allergy 2010; 65: 1357-1366.

29. Campagna JD, Bond MC, Schabelman E, Hayes BD. The use of cephalosporins in penicillin-allergic patients: a literature review. J Emerg Med 2012; 42: $612-620$.

30. Baldo BA, Pham NH, Weiner J. Detection and side-chain specificity of IgE antibodies to flucloxacillin in allergic subjects. J Mol Recognit 1995; 8: 171-177.

31. Zagursky RJ, Pichichero ME. Cross-reactivity in beta-Lactam Allergy. J Allergy Clin Immunol Pract 2018; 6: 72-81 e71.

32. Romano A, Gueant-Rodriguez RM, Viola M, Pettinato R, Gueant JL. Crossreactivity and tolerability of cephalosporins in patients with immediate hypersensitivity to penicillins. Ann Intern Med 2004; 141: 16-22.

33. Goodman EJ, Morgan MJ, Johnson PA, Nichols BA, Denk N, Gold BB. Cephalosporins can be given to penicillin-allergic patients who do not exhibit an anaphylactic response. J Clin Anesth 2001; 13: 561-564. 
34. Macy E, Contreras R. Adverse reactions associated with oral and parenteral use of cephalosporins: A retrospective population-based analysis. J Allergy Clin Immunol 2015; 135: 745-752 e745.

35. Blondel B, Coulm B, Bonnet C, Goffinet F, Le Ray C, National Coordination Group of the National Perinatal S. Trends in perinatal health in metropolitan France from 1995 to 2016: Results from the French National Perinatal Surveys. J Gynecol Obstet Hum Reprod 2017; 46: 701-713. 
Table 1. Clinical classification of penicillin allergy depending on the allergy history.

\begin{tabular}{lr}
$\begin{array}{l}\text { Self-reported symptoms of penicillin } \\
\text { allergy }\end{array}$ & Risk level \\
\hline $\begin{array}{l}\text { Diarrhea, nausea, vomiting, abdominal } \\
\text { pain }\end{array}$ & $\begin{array}{r}\text { Level 0. Probably no allergy } \\
\text { Vertigo }\end{array}$ \\
$\begin{array}{l}\text { Fever } \\
\text { Mycosis }\end{array}$ & $\begin{array}{l}\text { No contraindication to penicillins } \\
\text { Use of penicillin desirable if indicated }\end{array}$ \\
\hline $\begin{array}{l}\text { Cutaneous eruption } \\
\text { Delayed urticaria } \\
\text { Doesn't know }\end{array}$ & $\begin{array}{l}\text { Level 1. Severe allergy improbable } \\
-\quad \text { Cephalosporins desirable } \\
\text { if } \beta \text {-lactams are indicated }\end{array}$ \\
\hline $\begin{array}{l}\text { Hospitalization for allergies } \\
\text { Anaphylactic shock } \\
\text { Malaise with loss of consciousness }\end{array}$ & Level 2. High risk of serious allergy \\
$\begin{array}{l}\text { Facial edema, angioedema } \\
\text { Asthma, respiratory problems, feeling of } \\
\text { suffocation }\end{array}$ & \\
\hline
\end{tabular}

${ }^{\mathrm{a}}$ Prefer cefazolin or third- or fourth-generation cephalosporins. 
Table 2. Women's general and obstetric characteristics before or after the educational intervention.

\begin{tabular}{|c|c|c|c|}
\hline & $\begin{array}{l}\text { Preintervention } \\
n=903\end{array}$ & $\begin{array}{l}\text { Postintervention } \\
\mathrm{n}=892\end{array}$ & $P$ \\
\hline Age $(\text { years })^{\mathrm{a}}$ & $30.7 \pm 5.4$ & $30.8 \pm 5.2$ & 0.69 \\
\hline Nulliparous & $351(38.9 \%)$ & $380(42.6 \%)$ & 0.11 \\
\hline Smokers & $123 / 812(15.1 \%)$ & $102 / 823(12.4 \%)$ & 0.11 \\
\hline Body mass index $\left(\mathrm{kg} / \mathrm{m}^{2}\right)^{\mathrm{a}}$ & $24.1 \pm 5.3$ & $24.7 \pm 5.7$ & 0.02 \\
\hline Reported allergy to penicillin & $61(6.8 \%)$ & $48(5.4 \%)$ & 0.24 \\
\hline Gestational age at delivery (weeks) & $38.8 \pm 2.6$ & $38.8 \pm 2.7$ & $>0.99$ \\
\hline Preterm birth (Birth < 37 weeks) & $97(10.7 \%)$ & $68(7.6 \%)$ & 0.02 \\
\hline In utero death & $13(1.4 \%)$ & $10(1.1 \%)$ & 0.59 \\
\hline \multicolumn{4}{|l|}{ Mode of labor onset } \\
\hline - Spontaneous & $9(67.4 \%)$ & $9(64.9 \%)$ & \\
\hline - Induction of labor & $7(25.1 \%)$ & $5(25.2 \%)$ & 0.28 \\
\hline - Cesarean before labor & $(7.3 \%)$ & $(9.3 \%)$ & \\
\hline Cesarean delivery & $146(16.2 \%)$ & $173(19.4 \%)$ & 0.07 \\
\hline Birth weight $(g)^{\mathrm{a}}$ & $3260 \pm 650$ & $3250 \pm 670$ & 0.90 \\
\hline Transfer to NICU ${ }^{\mathrm{b}}$ & $37(4.0 \%)$ & $44(4.9 \%)$ & 0.73 \\
\hline
\end{tabular}

${ }^{\text {a }}$ Values for age, body mass index, gestational age at delivery and birth weight are mean \pm standard deviation.

${ }^{\mathrm{b}} \mathrm{NICU}=$ Neonatal Intensive Care Unit. 
Table 3. Classification of allergies according to allergy history and prescription of antibiotic therapy.

\begin{tabular}{llll}
\hline & $\begin{array}{l}\text { Preintervention } \\
\mathrm{n}=61\end{array}$ & $\begin{array}{l}\text { Postintervention } \\
\mathrm{n}=48\end{array}$ & $P$ \\
\hline $\begin{array}{l}\text { Classification of allergies by history } \\
\text { Risk level }\end{array}$ & $42(68.9 \%)$ & $48(100.0 \%)$ & $<0.001$ \\
$\quad$ - 0: Probably no allergy & $2(3.3 \%)$ & $6(12.5 \%)$ & \\
- 1: Severe allergy improbable & $31(50.8 \%)$ & $27(56.3 \%)$ & 0.18 \\
- 2: High risk of serious allergy & $9(14.8 \%)$ & $15(31.3 \%)$ & 0.44 \\
\hline Antibiotic therapy during pregnancy or delivery & $29(47.5 \%)$ & $27(56.3 \%)$ & \\
\hline
\end{tabular}


Table 4. Antibiotic therapy during pregnancy or delivery among women who self-reported penicillin allergy.

\begin{tabular}{llll}
\hline & $\begin{array}{l}\text { Preintervention } \\
\mathrm{n}=29\end{array}$ & $\begin{array}{l}\text { Postintervention } \\
\mathrm{n}=27\end{array}$ & $P$ \\
\hline Appropriateness of the antibiotic therapy & $5(17.2 \%)$ & $18(66.7 \%)$ & $<0.001$ \\
Antibiotic therapy & & & \\
$-\quad$ Only during pregnancy & $2(6.9 \%)$ & $3(11.1 \%)$ & 0.24 \\
$-\quad$ Only during delivery & $22(75.9 \%)$ & $23(85.2 \%)$ \\
$-\quad$ Both & $5(17.2 \%)$ & $1(3.7 \%)$ & \\
\hline
\end{tabular}


Table 5. Type of the antibiotics administered depending on the risk level of penicillin allergy.

\begin{tabular}{|c|c|c|c|c|}
\hline Risk level & $\begin{array}{l}\text { Preintervention } \\
\mathrm{n}=29\end{array}$ & Antibiotic therapy & $\begin{array}{l}\text { Postintervention } \\
n=27\end{array}$ & $\mathrm{p}$ \\
\hline & $\mathrm{n}=2$ & & $\mathrm{n}=3$ & \\
\hline 0 & $1(50.0 \%)$ & Penicillins & $2(66.7 \%)$ & $>0.99$ \\
\hline \multirow[t]{3}{*}{ Probably no allergy } & - & Cephalosporin & $1(33.3 \%)$ & \\
\hline & $1(50.0 \%)$ & Macrolides & - & \\
\hline & $\mathrm{n}=15$ & & $\mathrm{n}=13$ & \\
\hline 1 & $1(7.1 \%)$ & Cephalosporin & $5(38.5 \%)$ & \\
\hline \multirow{3}{*}{$\begin{array}{l}\text { Severe allergy } \\
\text { improbable }\end{array}$} & $3(14.3 \%)$ & Penicillins & - & 0.07 \\
\hline & $11(78.6 \%)$ & Macrolides & $6(46.2 \%)$ & \\
\hline & - & Other* & $2(15.4 \%)$ & \\
\hline \multirow[b]{2}{*}{ 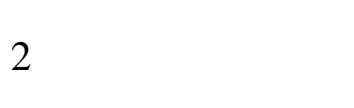 } & $\mathrm{n}=3$ & & $\mathrm{n}=11$ & \\
\hline & $3(100 \%)$ & Macrolides & $11(100 \%)$ & \\
\hline \multirow{2}{*}{$\begin{array}{l}\text { High risk of serious } \\
\text { allergy }\end{array}$} & - & Penicillins & - & $>0.99$ \\
\hline & - & Cephalosporin & - & \\
\hline \multirow{4}{*}{ Unclassified } & $\mathrm{n}=9$ & & $\mathrm{n}=0$ & \\
\hline & $1(11.1 \%)$ & Penicillins & - & \\
\hline & $1(11.1 \%)$ & Cephalosporin & - & - \\
\hline & $7(77.8 \%)$ & Macrolides & - & \\
\hline \multirow{5}{*}{ Total } & $7(24.1 \%)$ & $\beta$-lactams & $8(29.6 \%)$ & \\
\hline & $5(17.2 \%)$ & - Penicillins & $2(7.4 \%)$ & \\
\hline & $2(6.9 \%)$ & - Cephalosporins & $6(22.2 \%)$ & $0.56^{\mathrm{b}}$ \\
\hline & $22(75.9 \%)$ & Macrolides & $17(63.0 \%)$ & \\
\hline & - & Other $^{\mathrm{a}}$ & $2(7.4 \%)$ & \\
\hline
\end{tabular}

The antibiotic class in bold is recommended for the corresponding risk level.

a 2 women received fluoroquinolones, which were more appropriate for the infection (according to the antibiotic susceptibility testing); this antibiotic therapy was considered correct.

${ }^{\mathrm{b}} \beta$-lactams vs. other. 